\title{
LA TRANSICIÓN SOCIAL A LA DEMOCRACIA
}

\author{
Alberto Mayol Miranda
}




\section{ALBERTO MAYOL MIRANDA}

Sociólogo y Magíster en Ciencia Política de la Universidad de Chile, Licenciado en Estética de la Pontificia Universidad Católica de Chile, DEA en Teoría Sociológica de la Universidad Complutense de Madrid y candidato a Doctor en Teoría Sociológica de la misma Universidad. Profesor asistente de la Facultad de Ciencias Sociales de la Universidad de Chile. Investigador del Centro de Investigación en Estructura Social. Ha trabajado como coordinador y encargado de la línea de cultura y estructura social en el Centro de Investigación en Estructura Social (CIES), proyecto Milenio que se desarrolló entre 2009 y 2011. Es miembro del comité editorial y redactor de la sección "Cultura" de la Revista Análisis del Año del Departamento de Sociología de la Universidad de Chile. Actualmente prepara la publicación del libro El Chile Profundo: cultura de la desigualdad en el Chile contemporáneo. Sus áreas de especialidad son: sociología política, sociología de la cultura y del arte, investigación social y filosofía de la ciencia. Es docente en las carreras de sociología y antropología de la Universidad de Chile, panelista del programa radial Semáforo y co-conductor de La República de las Letras, ambos programas de la emisora de la Universidad de Chile. 


\section{LA TRANSICIÓN SOCIAL A LA DEMOCRACIA ${ }^{1}$}

\section{INTRODUCCIÓN}

¿Es una revuelta o es una revolución? Es la pregunta que recorre (implícita o explícita) el Palacio de Gobierno chileno en este 2011. La mera suma de los miles de ciudadanos en las calles, con demandas inverosímiles en los tiempos de la abulia; la intromisión ciudadana en el proceso de toma de decisiones de la clase política; estos han sido motivos suficientes para convocar los más variados análisis sobre la política y la sociedad del Chile actual. La necesidad de examinar aquí la adopción de movimiento de la sociedad civil, la necesidad de comprender qué pasó con el dique institucional que sostenía la tolerancia con el orden y el modelo, la imperiosa búsqueda sobre el significado del malestar y el cómo se enganchan estos asuntos con el pasado inmediato, son el objeto de este artículo. Y al respecto, se pretende simplemente señalar que no solo se debe mirar al sujeto de esta oración (el movimiento social anclado en el malestar), sino además al predicado, que sin ser protagonista directo parece ser parte importante de la explicación de lo ocurrido. Y al respecto se hace imprescindible observar las instituciones, su operación histórica permanente y su función específica desde 1990. La idea de un dique institucional que contenía las aguas de las demandas y del malestar y que dejaba la política de palacio salvaguardada de las presiones propias de la democracia es, grosso modo, la argumentación a proponer. La idea que complementa lo anterior, en cualquier caso, es más radical: ese dique parece haberse horadado por deslegitimación y su inoperancia plantea hoy un escenario nuevo, que ha quedado en evidencia por las manifestaciones multitudinarias de mayo y junio de 2011.

\section{NADA VIENE DE LA NADA}

No es novedad. Los partidos políticos no cesan de cesar². No es novedad: la clase política es significada como la clase abusadora en medio de una ciudadanía que se siente la

1. El autor desea reconocer el trabajo acumulado en el Centro de Investigación en Estructura Social como fuente fundamental de comprensión de estos fenómenos. La articulación de la amplitud de las temáticas abordadas aquí solo fue posible gracias al trabajo conjunto con el profesor Rodrigo Baño y con el equipo de ayudantes investigativos, donde han sido fundamentales Carla Azócar, Carlos Azócar y Javiera Araya.

2. La desconfianza en los partidos políticos ha aumentado en 10\% desde 1995 hasta 2009, llegando en la última medición del Latinobarómetro al 60\%, y con niveles máximos en algunas mediciones (2004 y 2008) a niveles que bordearon el $70 \%$. 
clase abusada ${ }^{3}$. El Congreso sigue cayendo aun después de haber conocido el abismo ${ }^{4}$. No es novedad, pues los políticos, presurosos por mitigar su inoperancia ${ }^{5}$, se refugian en las faldas de la Iglesia católica cuando un conflicto cualquiera así lo exige, sean mapuches, trabajadores o secundarios ${ }^{6}$. No es novedad: las mismas faldas de la Iglesia se contaminan y su legitimidad se derrumba por la mácula pervertida de sus hábitos ${ }^{7}$. No es novedad, la mercantilización absoluta deja a los sujetos expuestos ante un mundo incierto y hostil ${ }^{8}$. No es novedad, por el mundo recorren malestares de los nuevos tiempos y sus desamparos ${ }^{9}$. No es novedad, el desarrollo del país ha ido asociado a una

3. Investigación cualitativa de la línea "Cultura y Estructura Social" del Centro de Investigación en Estructura Social de la Universidad de Chile, 2009-2010. Véase: www.ciesmilenio.cl.

4. La desconfianza en el Congreso ha aumentado en 10\% desde 1995 hasta 2009, llegando en la última medición del Latinobarómetro al 60\% y con niveles máximos en algunas mediciones (2004 y 2008) a niveles que bordearon el 70\%. Pero no solo esto. Si cambiamos de encuesta para observar qué ocurre después de 2009, veremos que mientras en abril de 2010 la aprobación/desaprobación del Senado era de $44 \% / 33 \%$, esa cifra ha ido mutando vertiginosamente y en mayo de 2011 es de $30 \% / 55 \%$. La Cámara de Diputados muestra en mayo de 2011 una cifra aun más intensamente negativa: 24\%/59\%.

5. En 1995 el 66,5\% manifestaba desconfianza en los partidos políticos. La cifra ha crecido hasta un $75,3 \%$ en 2009, según la Encuesta Latinobarómetro.

6. En octubre de 2010 la Iglesia fue convocada a mediar por la huelga de hambre de comuneros mapuche. En agosto de 2007 la Conferencia Episcopal irrumpió instalando el debate sobre el salario ético, que se convirtió en base de la proyección de los proyectos de la derecha (Longueira, Kast, Piñera) y de la Concertación (el sistema de protección social de alguna manera fue un discurso enfatizado para hacerse cargo de la problemática). En junio de 2006 la "Revolución Pingüina", movimiento de estudiantes secundarios contra la Ley Orgánica Constitucional de Educación y en demanda de mayor calidad, terminó en un Consejo Asesor Presidencial donde la Iglesia tuvo papel protagónico. En septiembre de 2006 un conflicto entre el gobierno de Michelle Bachelet y la Confederación de Trabajadores de la Salud (Confenats) supuso la oferta de Monseñor Alejandro Goic para mediar en dicho conflicto. Ese rol mediador quedó establecido en Chile como rasgo de la cultura política desde la dictadura de Augusto Pinochet (1973-1990). La acción favorable en lo estructural al gobierno de Pinochet (combate al comunismo) y de apoyo a las redes sociales de resistencia, generando una defensa antidictatorial en los espacios microsociales, dio a la Iglesia católica una enorme fuente de legitimidad y un sitio en los conflictos relevantes del país.

7. Las confesiones de la propia Iglesia respecto a actos de pedofilia en Irlanda (Carta a los Católicos de Irlanda de Benedicto XVI el 19 de marzo de 2010), luego de enormes presiones por acumulación de casos de abusos sexuales; impactante para Chile resultaron las denuncias contra Fernando Karadima (de gran impacto por ser propietario político de un feudo fundamental en Chile, la Parroquia El Bosque, cuyo sencillo nombre no da luz sobre sus influencias y poder económico) y Sor Paula (Colegio Las Ursulinas de Maipú). Más relevante en las altas esferas resultó anteriormente la denuncia contra el Fundador de la Congregación Legionarios de Cristo, Marcial Maciel, cuyas denuncias se realizaron en 1997. En julio de 2010, sin embargo, el tema pasa a ser de relevancia política, con la intervención económica que el Vaticano realiza sobre la Congregación, dando un golpe a su autonomía y autogobierno.

8. Ver al respecto Sennett, R., La cultura del nuevo capitalismo, Barcelona: Anagrama, 2006. Más claro respecto al desamparo que las dinámicas desreguladoras suponen es Stiglitz, Josef, El Malestar en la Globalización, Madrid: Taurus, 2002.

9. Bauman ha propuesto la palabra alemana unsicherheit para describir los rasgos conjuntos de incertidumbre, inseguridad y desprotección que implican temer el ataque de otro, no tener claro qué podría pasar en el futuro y sentirse abandonado en esta situación. Véase: Bauman, Z., En busca de la política, México: Fondo de Cultura Económica, 2002. 
desafección entre los marcos normativos con respecto al sistema político ${ }^{10}$. En términos específicos el proceso de democratización no logra establecer un relato sobre sí mismo que dé sentido a los cambios experimentados a todo nivel. No es novedad, desde siempre los caminos institucionales parecen estar aprisionados desde arriba y quienes desean inundarlos desde abajo deben usurpar la palabra. No es novedad, la Concertación había de morir sin Pinochet pues solo había logrado ser su alter ego ${ }^{11}$. No es novedad, gerenciar compañías con el estímulo del despido no es lo mismo que gobernar un pueblo con la exigencia de la legitimidad. Nada hay de nuevo bajo el sol. Y, sin embargo, parece que hubiésemos cambiado nuestros giros. Parece que una nueva revolución gobierna la trayectoria de nuestra órbita planetaria.

Cada evento por su cuenta, no es novedad alguna. Pero todos los eventos juntos y los matices implicados han convertido este en un escenario completamente nuevo. El año 2011 ha sorprendido con sus avatares: la crisis de legitimidad producida por Hidroaysén, las movilizaciones por la educación pública, la caída del gobierno y la oposición en las encuestas, unidos más en la muerte que en la gloria, fueron síntomas de un impreciso algo que parecía buscar vías de expresión. Se le denominó "malestar", referencia esta al informe carácter de la energía social y activa de una demanda que, sin embargo, trasciende todo texto, todo petitorio y que se relaciona con el todo de la sociedad, que nos dice que en cualquier caso la sociedad es un tejido infinito cuyos hilos siempre remiten a otros. Malestar y bienestar son las formas sinceras de lo político, sus confines, el horizonte de sentido. Por lo tanto, la presencia del malestar social en Chile es ante todo la politización de lo social. No se debe entender esto del modo inmediato que las visiones sobre la política han instalado ${ }^{12}$. La política tiene tres dimensiones: el palacio (arte de gobernar), las políticas públicas (arte y/o ciencia de ejecutar) y la polis (articulación de los intereses y las voluntades). La dimensión más débil en la transición chilena fue la polis, desarticulada activamente por su carácter complejo para una democracia tutelada y abierta solo "en la medida de lo posible"13. Privilegiadas las dos primeras dimensiones (palacio y políticas públicas), la demanda ciudadana era utopía

10. Véase: Lechner, N., Obras escogidas. Volumen 1, Santiago de Chile: LOM, 2006.

11. Señalado ya en 2007 en la página 279 del Postfacio de la Revista de Sociología de la Universidad de Chile, los editores señalan que desde 1990 hasta 2007 "la Concertación expresa (...) una historia de consolidación y quizás de decadencia política que parece respetar -casi mecánicamente- las leyes de la historia como contraparte simbólica de Pinochet: la lucha contra él dio fortaleza y épica a su labor, mientras la muerte del ex dictador parece ir acompañada por síntomas de desintegración".

12. Las acusaciones sobre ideologización de los movimientos sociales o influencia de partidos políticos en los estudiantes se han multiplicado en el año 2011. Condensación de esta visión es la editorial del periódico El Mercurio del día viernes 1 de julio de 2011. Se puede acceder en http://blogs.elmercurio. com/editorial/2011/07/01/radicalizacion-estudiantil-y-e.asp

13. El 31 de diciembre de 1990, en vísperas de Año Nuevo, el Presidente Patricio Aylwin Azócar señaló que era indispensable continuar "la tarea ineludible de esclarecer la verdad y hacer justicia, en la medida de lo posible, respecto a situaciones del pasado aún pendientes, o que constituyen heridas abiertas en el alma nacional". Esto fue dicho con relación a la configuración de la Comisión de Verdad y Justicia. La frase se transformó en el símbolo político de la transición a la democracia, por las graves consecuencias para la democracia de marcar verdades y justicias en la medida de lo posible. 
sinsentido y la medida de lo posible la marcó la clase política. La irrupción del malestar es el arribo de un verosímil antes devaluado: los proyectos de la ciudadanía son relevantes, deben ser atendidos y resultan posibles. Este último punto no parece todavía tener consumación en la cultura chilena sobre lo político, pero los dos primeros sí han logrado hacerse presentes este 2011. El cambio del proyecto energético Barrancones ${ }^{14}$, la crisis de Hidroaysén ${ }^{15}$ y el movimiento social más relevante desde la dictadura (desatado por los esfuerzos del gobierno de producir una reforma en la educación superior que radicalizara el modelo existente) ${ }^{16}$; han invitado a la perplejidad, al bosquejo, a la osadía interpretativa, a la miopía intelectual y a la revisión de esos datos que antes hablaban en un idioma y hoy parecen requerir una traducción o al menos una interpretación cifrada. La intelectualidad ha tenido que dar razones y conjeturas allí donde también debieran haber excusas por el tiempo perdido.

Para ser honestos con los datos, la culpa no era de ellos. Para su desgracia, dependen ellos de sus analistas, como este modesto escribano. Y los analistas, que son humanos, dependen mucho del clima intelectual y sus paradigmas ${ }^{17}$. Y los datos eran enfáticos: la tasa de suicidios aumentaba radicalmente desde $1990^{18}$ y el consumo de antidepresivos hacía lo propio en semejante y hasta más radical tendencia ${ }^{19}$. Más aun, en la investigación desarrollada en el Centro de Investigación en Estructura Social (CIES) de la Universidad de Chile, la primera certeza que recorrió de modo abismante las observaciones fue la acreditación del malestar como el hecho principal en juego en la estructura social chilena ${ }^{20}$. No es menor, se debe enfatizar la observación de los indicadores de salud pública (como los mencionados suicidios y consumo de antidepresivos), pues ellos son el

14. En agosto de 2010 y derivado de pequeñas movilizaciones y mucha presencia en redes sociales de la defensa de Punta de Choros, como se conoce turísticamente la zona. En la ocasión el Presidente tuvo que reconocer haber realizado una gestión personal, fuera de la institucionalidad, para satisfacer a la ciudadanía.

15. El sábado 28 de mayo de 2011 se congregaron alrededor de 20000 personas para marchar en protesta contra el proyecto energético Hidroaysén, consistente en una enorme represa en la Patagonia y una red de cableado para suministrar energía varios miles de kilómetros más al norte del país.

16. Las movilizaciones desde mayo a junio han sido múltiples. Más de 40 colegios en toma, alrededor de 20 universidades en paro o en toma, dos manifestaciones de 80.000 personas según el gobierno y solo en Santiago, aunque la del 30 de junio congregó en todo el país al menos 300.000 personas. El Consejo de Rectores de las Universidades de Chile ha apoyado las movilizaciones e incluso colegios particulares han ingresado a las movilizaciones. Al escribir este artículo, estos eventos están en desarrollo.

17. Como ha señalado Thomas Kuhn sistemáticamente. Al respecto revisar Kuhn, T., La Estructura de las Revoluciones Científicas, Fondo de Cultura Económica, 1995.

18. En rigor se ha duplicado. Ver Rojas, I., Presentación "Plan Nacional de Prevención del Suicidio" en Jornada Suicidio en Chile, Perspectivas Actuales, Santiago: Pontificia Universidad Católica de Chile, abril, 2008. URL: http://www.psiquiatriauc.cl/system/files/Jornada-Suicidio_Presentacion_Sra_Irma_Rojas.pdf

19. Entre 1990 y 2004 el consumo de antidepresivos creció en un 470,2\% en Chile. Ver Jirón, Marcela et. al, "Consumo de Antidepresivos en Chile entre 1992 y 2004" en Revista Médica de Chile, Na 136, Santiago: 2008, págs. 1147-1154.

20. Aparece en los textos desarrollados en 2010 (www.ciesmilenio.cl) y en la presentación preparada por este investigador (denominada "Investigar la desigualdad: problemas de iluminación", en el Taller Binacional "Redes de Investigación sobre Desigualdades Sociales (Chile-Alemania): conceptualizar las desigualdades sociales", realizado en Santiago el 14 y 15 de marzo de 2011. 
punto de condensación de eso que llamamos bienestar (o de su antípoda). No en vano la metáfora fundamental en las entrevistas cualitativas sobre el dolor de pertenecer a los humillados y ofendidos radica siempre en el hospital como punto de anudamiento de los significados amplios y variados sobre el dolor, el malestar, la utópica "atención" y la sanación como esperanza marchita. Es cierto, también lo dicen los datos, que en el mismo período crecía la economía, el ingreso, el desarrollo humano, la felicidad y la satisfacción. ¿Cómo se puede ser feliz e infeliz a la vez? Para que esto fuese posible, la operación despolitizadora había sido fundamental, se ha argumentado desde las indagaciones llevadas a cabo en el CIES de la Universidad de Chile. La expectativa personal aparece desproporcionada a las señales de la realidad. En promedio, como resultado de la Encuesta Metropolitana 2010, se piensa que en diez años se llegará a tener una posición social del doble de la actual. Esto se radicaliza en los sectores medios-bajos, aun cuando los datos de movilidad no respaldan la proyección y aun cuando los indicadores de calidad educativa en esos grupos son muy malos y no reflejan la aparición de los espacios y condiciones de crecimiento ${ }^{21}$. De este modo, es la fantasía una de las fuentes de mitigación del malestar, la esperanza tan energética como improbable en un futuro radicalmente mejor. Otras fuentes de mitigación serán la analgesia ("el colegio de mis hijos no es tan malo, al menos tiene valores") y la adaptación ("yo puedo estar en desacuerdo, pero debo adaptarme")22. Todas pueden ir juntas; en cualquier caso, su operación no es excluyente, sino más bien lo contrario. Pues bien, el asunto es que un sujeto despolitizado está al mismo tiempo arrojado al mundo a su suerte tanto para bien como para mal. Es libre para emprender y quizás pueda llegar muy lejos. Está, sin embargo, tan libre como solo. La despolitización es fundamentalmente la pérdida de referentes en la horizontalidad, la incapacidad de reconocer voluntad e intereses como partes constitutivas de la sociedad y su organización. El ciudadano despolitizado pierde referentes: no entiende que su vecino de sesenta años es en alguna medida él mismo, que sus compañeros de trabajo son en alguna medida él mismo. Ese ciudadano, mediante esta operación, puede sentirse al mismo tiempo al borde de la caída o de la divinización. Aristóteles decía que fuera de la sociedad están solamente los animales y los dioses. En Chile se ha hecho política de la divinización de unos y se ha hecho política de la animalización de otros ${ }^{23}$. Y en ese tránsito se ha destruido la política.

En un entorno despolitizado, la sociedad puede declarar ser más feliz y al tiempo ser muy frágil en transitar por el camino que conduce a la frustración. El área de lo político queda reducida y su capacidad integrativa también. No pertenecer, no ser, supone no ser reconocido como sujeto político con voluntades e intereses.

21. Véase: CIES Universidad de Chile: Siete Fenómenos sobre Educación y Desigualdad en Chile, Santiago: Documento de trabajo CIES. 2010. URL: http://www.ciesmilenio.cl/wp-content/uploads/2011/03/ DESIGUALDAD-Y-EDUCACION-INFORME-CIES-U-DE-CHILE.pdf

22. Véase: CIES Universidad de Chile: El Chile Profundo. Cultura de la desigualdad en el Chile Contemporáneo. Santiago: Documento de trabajo CIES, síntesis en www.ciesmilenio.cl., 2010.

23. Dioses, humanos, animales; es la tríada fundamental que traduce ricos, clases medias y pobres en Chile, que a su vez se proyecta en una estructura tripartita que siempre divide la realidad de clases en tres y que la proyecta como forma de concebir toda incorporación del otro. Esto se puede revisar en www. ciesmilenio.cl 
Lo cierto es que el malestar se ha expresado. Desconoció este hecho la sentencia tan socorrida anteriormente que señalaba nuestra despolitización como resultado "natural" del tránsito al desarrollo, pues en él los asuntos públicos son menos relevantes (entendiendo lo público como asunto de pobres). Ahora se señala que la expresión politizada del malestar en múltiples y energéticas manifestaciones se debe al típico malestar de los 15 mil dólares ${ }^{24}$. ¿Qué pensar? Es acaso la politización o la despolitización el sino trágico del desarrollo. No se dice, por cierto, o al menos no al mismo tiempo, que Chile no ha llegado al desarrollo. No se dice, tampoco, que ni siquiera ha llegado a los 15 mil dólares y que de hecho todavía no llegamos a 12 mil. No nos dicen, además, que aun cuando llegásemos a 15 mil dólares o a 20 mil dólares, no podríamos hablar de desarrollo con nuestra desigualdad, que arroja al pleno tercer mundo al 80\% de la población. No dice el argumento que las sociedades desiguales normalmente tienen mucho malestar por eso mismo y que normalmente se politizan por necesidad. No dice el argumento que cuando ello no ocurre, cuando todo queda invisibilizado, es porque se construyeron diques que evitan la inundación de la órbita política por los problemas sociales. No dice, en ese argumento, que esa es la historia de Chile.

Volvamos, sin embargo, a la problemática del malestar y sus vínculos con la subjetividad, clave para comprender lo que está ocurriendo. Chile lleva años mostrando una fuerte promoción del vínculo del sujeto con las instituciones ${ }^{25}$, pero no un vínculo sólido con la política o entre los ciudadanos. Debemos sumar la completamente conflictiva relación con el otro (cualquiera sea), el que es visto o como el superior divinizado o como el inferior animalizado. Finalmente, más importante que todo lo anterior, se diagnostica la existencia de un claro desajuste entre los valores y marcos normativos que configuran el repertorio de sentido de la sociedad chilena y la existencia material de la misma, que demanda interpretaciones para condiciones de existencia muy distintas. Para ser exactos, la vida económica, complejizada y operacionalmente mucho más sofisticada que treinta años atrás, es leída en un código estrictamente moral, que hace inaprehensible la comprensión por parte del sujeto de las operaciones que ejecuta. También la política, desprovista de sentido de conflicto y de legitimidad en la expresión de sus contenidos, se ve castrada y no es una dimensión legítima de existencia cultural. Retraído a una moralización banalizante, el sujeto parece carecer de las condiciones para comprender su propia existencia.

Sin embargo, no es solo mera inadecuación entre sentidos y operaciones funcionales lo que explica el malestar. Hay además una marcada presencia de la injusticia como atributo de esta sociedad. Se interpreta desde tres visiones: el determinismo histórico de ciertas injusticias (la dimensión atávica), la clausura o falsedad de las oportunidades basadas en el mérito (el diagnóstico del acceso como relato sin trasfondo) y finalmente

24. "La Ira de los 15.000 dólares", por Ascanio Cavallo, en La Tercera, jueves 18 de junio de 2011. Ver en http://blog.latercera.com/blog/acavallo/entry/la_ira_de_los_15

25. Como muestran los análisis del CIES, los chilenos consideran que el proceso de desarrollo en Chile tiene la ventaja que otorga el respaldo de instituciones fuertes, a diferencia de otros países de América Latina. Esto también se ve confirmado por la Encuesta de Cohesión Social en América Latina, en donde Chile resulta ser el país dentro de la región con mayor confianza en sus instituciones. Los análisis están publicados en formato electrónico en: www.ecosocialsurvey.org/, revisado en Mayo 2011. 
el abuso. Al respecto, la crisis de la promesa del mérito es la que arrastra el malestar educativo. Se ha prometido por años que, gracias a la educación como fuente legítima de ascenso social, cualquiera puede surgir. La radical mentira cobra hoy como principal víctima el sistema de oportunidades en Chile. La noción de abuso, por último, muy presente en el Chile actual (y que elaboramos en detalle más abajo) terminará por gatillar un resentimiento no solo por los efectos, sino además por sus significaciones. No se trata del malestar de estar perdiendo solamente; sino además de recibir sistemáticamente el recuerdo de ello y la acción proactiva para producirlo.

La sensación de vulnerabilidad, de ser víctima de abusos constantes, la insatisfacción con la situación del país, con el modelo económico y con la desigualdad; la convicción de habitar una serie de contradicciones y paradojas que hacen de los movimientos de cada biografía una especie de tránsito a la aporía, cuando no a la tragedia; la sensación de estar siendo atacados y extinguidos (las clases medias diciendo que son sistemáticamente violentadas, los pobres señalando que son la clase abusada); la percepción de habitar una especie de prisión; la sensación del otro como enemigo activo y poderoso. Todos estos sentimientos constituyen constantes evidentes en los discursos y expresiones de los datos cuantitativos recopilados en el CIES.

Lo cierto es que en este Chile del crecimiento económico no son datos independientes el aumento del ingreso, el incremento en el desarrollo humano, el incremento de la felicidad, del estatismo, la despolitización, los suicidios y el consumo de antidepresivos. Hay una intensa energía que recorre esta sociedad. No ha sido canalizada por las instituciones, sino (muy por el contrario) ha sido detenida por ellas, contenida, mitigada en sus efectos. Una sociedad que altamente disconforme espera la resolución del dolor con la maquinaria analgésica a ratos, mesiánica en otros momentos, del Estado como solución última, pero desatendiendo la exigencia de politización que una visión saludable de Estado (propia de un entorno democrático) exige.

Cuadro 1. Índices Encuesta CIES

\begin{tabular}{|l|c|}
\hline Índices Encuesta CIES & Puntajes (desde 0 a 100) \\
\hline Índice de disconformidad con el orden existente & 66,1 puntos \\
\hline Índice de estatismo & 69,5 puntos \\
\hline Índice de percepción de lucha de clases ${ }^{27}$ & 74,6 puntos \\
\hline Índice de politización & 40,9 puntos \\
\hline Índice de individualismo & 59,9 puntos \\
\hline Índice de tolerancia al conflicto & 32,3 puntos \\
\hline
\end{tabular}

Fuente: Elaboración propia a partir de Encuesta Metropolitana CIES 2009.

26. Los índices se construyeron cada uno procesando conjuntamente un grupo de variables que respondieran a un diseño teórico de cada una de las nociones medidas. La medición va desde 0 (cero), significando siempre la ausencia total del atributo; hasta 100 (cien), que señalará la mayor intensidad en su presencia.

27. El índice de percepción de lucha de clases mide fundamentalmente qué tan contradictoria es vista la relación entre las clases sociales, entendiendo estas fundamentalmente en su expresión más intensa, que es la relación empresario/trabajador. 
Desde hace años sabemos que en Chile la ciudadanía preferiría un Estado fuertemente involucrado en los problemas ${ }^{28}$, sabemos también que se desea que la educación sea pública y estatal, que no pertenece al dogma de nuestra sociedad el libre mercado, que el modelo educacional es inviable ${ }^{29}$ y que la desprotección de la ciudadanía frente al sistema financiero es abismante. Desde hace años sabemos que nuestra estructura de impuestos es regresiva ${ }^{30}$, que el Estado focaliza sus beneficios en dos sitios: en los más pobres y en los empresarios. En los primeros en forma de mísera caridad hiperpublicitada; en los segundos cual si fuera un molto allegro e vivace, cuya danza infame es normalmente invisible a nuestros ojos ${ }^{31}$. Desde hace años sabemos que el sistema de AFPs también es inviable y que, sin embargo -pero por lo mismo siguiendo la lógica perversa que le dio origen-, se hace indispensable profundizar el modelo e invitar a cada cotizante a que ahora deposite más dinero para su futuro, evitando la caída futura de su estándar de vida, o al menos mitigando el desplome ${ }^{32}$.

Sabemos que hoy nos dicen que lo privado resolverá todo. Y claro, se muestran sistemas privados que atienden al 10\% de la población más rica y, gran novedad, funcionan mejor que el del 50\% más pobre. Será porque pueden cobrar veinte veces por lo mismo. Y ante ese ejemplo el ciudadano devenido en televidente se sorprende y piensa que quizás esa utopía de delantales limpios y maquinarias de última generación está al alcance de la mano. Sabemos que mañana, si todo llega a ser privado, nos dirán que no alcanza y que debemos generar un segundo sistema privado que apoye al primero (como en las pensiones), o que será necesario aumentar los costos y que el Estado deberá cobrar más impuestos para poder luego transferirlos a los privados. Es el camino largo: sacar dinero por el lado del mercado y también por el lado del Estado. Es lo que ha pasado en educación. Las universidades privadas y los colegios del mismo tipo dijeron que nacían solo en el mercado y que no necesitaban al Estado, sino solo

28. La encuesta Latinobarómetro nos muestra que el 46,3\% considera que el Estado puede resolver la mayor parte o todos los problemas del país y que, en cambio, la visión desestatizada suma un $28,2 \%$ (2009). Un 94\% considera que la salud debe estar mayoritariamente en manos del Estado, un 92\% piensa que debe ser igual con las pensiones, y el 65,5\% considera que el Estado debe ser además empresario, al señalar que la actividad productiva no se debe dejar a los privados solamente.

29. El modelo educacional está siendo actor activo en la reproducción de la desigualdad. Mientras en $4^{\circ}$ básico los puntajes SIMCE son semejantes en todas las comunas del país, en $2^{\circ}$ año de educación media los puntajes de las comunas más pobres han bajado desde su posición original y las comunas más ricas han crecido 60 puntos. Estos datos se encuentran disponibles en CIES Universidad de Chile: Siete Fenómenos sobre Educación y Desigualdad en Chile, Santiago: Documento de trabajo CIES. 2010. URL: http://www.ciesmilenio.cl/wp-content/uploads/2011/03/DESIGUALDAD-Y-EDUCACION-INFORME-CIES-U-DE-CHILE.pdf

30. Pocos impuestos a las empresas, alto Impuesto al Valor Agregado (IVA); son los símbolos de una más compleja cadena de impuestos desvinculados de la capacidad redistributiva.

31. Y sin embargo, se puede observar en políticas públicas como la Ley de Donaciones, el Crédito Universitario con Aval del Estado, el sistema de concesiones de autopistas y en la génesis del negocio salmonero; todos eventos, entre muchos otros, donde se diseñan políticas (o se ejecutan simplemente acciones, como las intervenciones al dólar) que favorecen a sectores empresariales concretos.

32. Y así el Ahorro Previsional Voluntario y las diversas formas de ahorro privado que eclosionan como salvavidas ante la certeza de una vejez sabidamente dificultosa. 
su prescindencia y abandono de lo público. Obediente, el Estado cumplió. Hoy, que su negocio es extraordinario, demandan no por necesidad, sino en el nombre de algo que incluso pueden llamar "justicia" y apelan al trato igualitario: al cubrir a parte importante de la población, el Estado debe respaldarnos, dicen, con una lógica que nos recuerda la muerte de Aristóteles y Russell juntos y unidos en la pena y la agonía.

Sabíamos que Chile es un país desmovilizado. $60 \%$ de la población, según la encuesta Latinobarómetro, considera que los movimientos sociales generan inestabilidad. El $72,6 \%$ considera que las manifestaciones y protestas "solo" producen desmanes y destrozos en las calles ${ }^{33}$. Sabíamos que la subjetividad que emanaba de estas condiciones se configuraba en la rebeldía contra un orden injusto (el país no se parece a lo que se desea y ni siquiera tiende a aproximarse a serlo) y en la aceptación de ese mismo país, pues los únicos caminos legítimos estaban en la institucionalidad. En el Centro de Investigación en Estructura Social le llamamos a este sujeto el "rebelde adaptativo". Consistente con lo anterior, nuestra cultura solo podía aferrarse a lo firme y lo cierto: Chile es un país hermoso, Chile es un país rico naturalmente, Chile tiene instituciones fuertes $^{34}$. Las aguas se quedaban quietas al enfrentar ese muro inmenso que eran las instituciones. En su interior, la clase política, no muy alejada de la elite económica, sino más bien conviviendo en el $2 \%$ superior de nuestra curva de ingreso; la clase política, decíamos, se protegió en las instituciones y se separó radicalmente del mundo social. Las aguas seguían creciendo por el lado de lo social, pero se la había domesticado y su forma de vida siempre debía ser en la quietud y la tibia complacencia. Y mucha agua quieta, aunque puede ser difícil de contener, es muchísimo menos complicada que las aguas en movimiento.

El malestar había crecido. Pero las instituciones eran un dique eficaz. Por supuesto, había que contar con esclusas, con reguladores. La Concertación ocupó brillantemente ese papel. Fue más su condición estructural que su habilidad (aunque también tuvo esta última alguna relevancia). Lo cierto es que la energía social, que no venía de la nada, se había acumulado durante años y de pronto las esclusas comenzaron a fallar. Además, le habían ofrecido el fin de los diques y el arribo al desarrollo. La promesa de ser un país rico es patrimonio de la derecha, aunque haya sido gestionada y promovida por la Concertación. Pues bien, era la hora de ser ricos, cada cual en su medida, pero todos. Ya gobernaba la derecha.

\section{DE DIQUES, ESCLUSAS E INUNDACIONES}

Una transición política construida a partir de un dique interpuesto entre la ciudadanía y las instituciones impedía que la acumulación de demandas y exigencias anegara la

33. Estos resultados están disponibles en línea en http://www.latinobarometro.org/latino/LATAnalize.jsp.

34. La investigación de la línea "cultura y estructura social" de la Universidad de Chile detectó una relación intensa con las instituciones y su fortaleza, entendiéndolas como protectoras y como herencia divina y vernácula, tan fuerte como la naturaleza misma. 
clase política. Apoyado en la desconfianza entre la ciudadanía -donde el discurso sobre la delincuencia es decisivo- y condicionado por el vínculo mesiánico con el Estado, la clase poseedora de este tenía garantías de ser la única fuente de decisiones. Las instituciones en nuestra cultura, residentes en la zona sagrada de la significación, eran tanto una fuente de estabilidad de una democracia frágil, como también de conservación de un orden visto como radicalmente injusto. Ese doble rol, celestial y demoniaco, ha estado siempre presente en la visión de los chilenos. La erótica de la fortaleza institucional siempre mitigó el malestar por lo segundo, pues el carácter divino de las instituciones, heredadas desde los tiempos inmemoriales, las suponía incuestionables. El siguiente esquema muestra algunos elementos significados positiva y negativamente por los chilenos a la hora de referir a Chile y sus rasgos fundamentales. Importante resulta entender que todo lo heredado y anterior es positivo (de alguna manera lo externo) y que todo lo actual y concreto es negativo (de alguna manera lo interno y especialmente lo que refiere al sujeto económico vinculado pobremente con la dimensión laboral ${ }^{35}$ ).

\begin{tabular}{|l|l|}
\hline Fortalezas de Chile & Debilidades de Chile \\
\hline Belleza y riqueza natural & Desaprovechamiento de recursos \\
\hline Amabilidad de la gente & Irresponsabilidad del chileno \\
\hline Tranquilidad & Delincuencia $^{36}$ \\
\hline Buen lugar para vivir & $\begin{array}{l}\text { Diferencias sociales, injusticias, diferencias entre } \\
\text { regiones y Santiago, exclusión }\end{array}$ \\
\hline País ordenado & País injusto. \\
\hline Instituciones fuertes & Política corrompida \\
\hline
\end{tabular}

Fuente: CIES.

Se debe insistir en la tendencia a la síntesis en la significación entre clase política, instituciones y ricos. Esta tríada es fundamental, pues su simbiosis, su anudamiento en un solo sitio de significación, implica que el encuentro de la ciudadanía con las instituciones implica retrotraerse a la situación de clase y a las posibilidades de movilización de capitales (sociales, económicos, culturales, políticos) que ello implica. Y dado que el orden social existente en Chile es radicalmente injusto en lo económico y que el resto de los capitales se han empeñado en generar una semejanza de familia relevante con la desigualdad económica, el problema se vuelve más estructural.

35. En el CIES se le llamó "pecador económico" para dar cuenta al carácter culposo de la relación de los chilenos con la economía y ante todo con la dimensión productiva.

36. La delincuencia no tiene una presencia relevante por el lado de los problemas materiales asociados al delito. La herida fundamental en nuestra cultura radica en la necesidad de desconfiar en el otro y perder así la comunidad deseada. 
Gráfico 1. Distribución del Ingreso por Percentiles

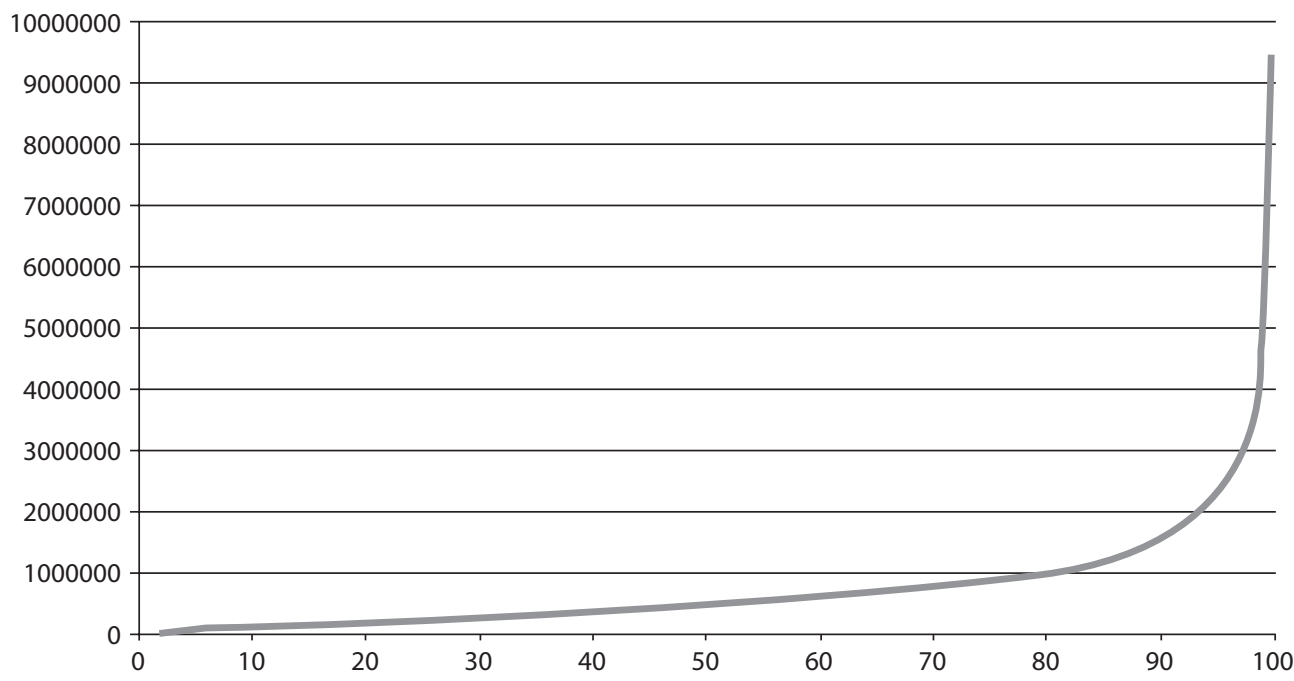

Fuente: CASEN 2009.

Esta desigualdad supone que quienes habitan las instituciones están objetivamente desanclados del resto de la sociedad. Los palacios de gobierno generan miopía con facilidad. Si la sociedad es extremadamente desigual, ello se incrementa. Las instituciones pasan a representar la desigualdad. Y aunque esa distancia puede tener bajo ciertas condiciones un signo positivo, pues el carácter divino de las instituciones solo puede consumarse con distancia, bajo otras condiciones puede representar la desesperación. Y es que bajo esta divinización los errores de las instituciones pueden parecer invisibles en principio, pero cuando se hacen irremediablemente visibles, su legitimidad se cuestiona. Cuando la desnudez desprotegida del ciudadano se vincula a la desnudez "de traje invisible" de las instituciones (el rey está realmente desnudo), se abre la puerta para observar el absurdo y se aprecia el carácter humillante de la mirada cenital de instituciones que ya no saben ver.

Pero hay más antecedentes. Se ha configurado una visión de las clases medias y bajas como clases abusadas, clases receptoras de dolor y violencia, pero también de indiferencia ante sus dolores. La clase media se logra distinguir en tanto parece ser capaz de procurarse de analgesia frente a ese dolor. La mera regresión de la cultura política hacia la comunidad de dolor es una señal de detrimento y menoscabo de la política y la ciudadanización. La comunidad de dolor es regresiva históricamente, es la primera forma comunitaria con lazos más allá de lo funcional. La investigación culturalista del CIES reportó este estatus a las condiciones de la cultura política chilena. La desigualdad se ha tornado fuerza activa no de la mera diferencia, sino incluso del abuso y la humillación. La legitimidad llega a sus límites operativos en esa condición. Finalmente, el abuso se constituye como la relación que define el vínculo entre el poderoso y el que no lo es, pasándose de la versión marcadamente negativa de opresión a la aun peor de 
abuso, donde la metáfora de fondo parece ser la sexual, lo que queda "confirmado" por la experiencia en la medida de las crisis sexuales que han rodeado a la política y la Iglesia católica.

Pero la desigualdad y los males que ella acompañaba parecían los males de los hombres, los males de la ejecución cotidiana del gobierno en la Tierra, los males de estos chilenos que no sabían qué hacer con la bella herencia recibida. Sin embargo, había un espacio celestial y puro en el que se sostenía la dignidad y el posible futuro. Para los chilenos la naturaleza del país, su belleza y riqueza, además de las fuertes instituciones que han sido forjadas desde los tiempos de los padres fundadores, son resguardo y baluarte moral. El chileno suele arruinar esta herencia con su obra cotidiana (piensa), pero es un beneficiado en herencia: ha recibido la perfección y la pureza de los grandes relatos sobre lo natural y lo social.

La grandeza de las instituciones operaba como maquinaria de procesamiento del malestar social. El dolor se asumía como parte de lo real, eventualmente producido por los humanos, eventualmente por el mercado. Pero las instituciones se entienden como cobijo y protección. El Estado, se ha visto en estudios cualitativos, debe operar como máquina procesadora de dolor: debe quitar la indignidad a los pobres y devolverlos a un dolor tolerable propio de la condición humana, debe mitigar por completo el dolor de las clases medias y debe concentrar todo el daño, todo castigo, en los delincuentes, lugar de expiación y consumo del dolor social recibido. En este marco las instituciones debían ser cuidadas, pues eran la contención del dolor. Y he ahí la Iglesia, el Congreso, el Gobierno, el Presidente, la Contraloría, los Partidos Políticos, el Banco del Estado y en definitiva la Ley. La fragilidad de una democracia reconquistada y tutelada condujo incluso a una ciudadanía ávida de proteger del conflicto a las instituciones. Mientras ellas debían ser capaces teóricamente de procesar el conflicto. Así, ante las amenazas recibidas, la ciudadanía prefirió eliminar el conflicto.

Sin embargo, la suma de los hechos puede horadar la fuerza de los dioses. A ratos se puede perdonar a lo divino su prescindencia, su distancia frente al dolor de lo real. Bastan para ello los sacerdotes y mediadores de todo poder intangible. Pero no se puede fundamentar la agresión como parte perdonable de la acción de las instituciones. Y se sumaron los casos: primero fue el caso Spiniak y su deriva hacia Jovino Novoa (y otros eventualmente), significado por la ciudadanía como el momento en que el padre (los políticos) abusan del modo más radical (sexualmente) de los niños de la casa. Posteriormente fue el Transantiago, donde se asumió que las políticas públicas se estaban haciendo prescindiendo de todo interés por dar dignidad a los ciudadanos. La política fue humillante y agresora. Luego fue la Iglesia y la pedofilia, vulnerando la confianza básica de la institución que logró que los niños fuesen a ella, que fue símbolo de la unidad familiar, principal sostenedor de educación en el país, depósito de reservas morales para casos emblemáticos. Y luego, fue también el gobierno que, en pleno terremoto, mostró inoperancia y pasividad primero, para luego transitar a la acción dolosa de sentenciar la inexistencia de un tsunami cuya existencia terminó matando a algunos que creyeron en la institución y volvieron al llano. Los partidos políticos han llegado a su peor momento: la desaprobación de la Alianza por el Cambio es del 57\% y la de la Concertación es del 
67\%. Los políticos mienten, prometen lo que no van a cumplir, se llevan el dinero y el prestigio. Finalmente abusan.

La crisis de la Iglesia es particularmente decisiva. En Chile, cualquier conflicto relevante, en medio de gobiernos y congresos particularmente debilitados en su capacidad de mediación, suponían el llamado a la Iglesia como mediación. Ello implicaba consecuencias muy relevantes. En primer lugar, es un síntoma débil, pero un síntoma, de un Estado fallido, pues llamar a la Iglesia es llamar a otro Estado. Por tanto, necesariamente dicho llamado era un acto de sometimiento a voluntades ajenas y una pérdida del poder soberano. Pero esto va más allá. Sostener vicariamente la política con la fuerza de la Iglesia suponía un riesgo que terminó por hacerse realidad. Si las instituciones políticas estaban debilitadas y usaban de soporte a la Iglesia, la caída de esta última en su legitimidad implicó necesariamente un retroceso mayor de la legitimidad de la política. Acabado el sostén, la política se derrumbó más; el entramado cayó completo. Y, por tanto, después de los casos Karadima, Sor Paula, Maciel, en fin, toda una estructura de prestigio y sus capitales políticos se desplomaron en un solo sonido.

Es decir, si la relación entre la ciudadanía y lo institucional configura el escenario que nos permite entender el Chile de la transición política, parece ser la misma relación la que nos permitirá apreciar el Chile de la transición social. El análisis actualmente convocado por analistas y medios dice que el malestar aumentó tanto que llegó al punto que explotó, o dice que las nuevas dimensiones de habitar en un entorno de mayores recursos tienen como consecuencia inevitable el aumento de demandas. El argumento que defendemos acá es menos poético, pero no por ello menos relevante. Se sostiene aquí la caída del dique, la inutilidad de las esclusas y la inundación del sistema político. En estos asuntos hay una línea que distingue lo que acontece en un escenario y lo que ocurre en otro, hay una línea que es la puerta de acceso a una nueva realidad. Es la "experiencia liminar" ${ }^{37}$. Y aunque la experiencia que se puede convocar radica fundamentalmente en la primera marcha relevante (por la oposición al proyecto energético Hidroaysén), no es menos cierto que las condiciones estructurales para que esa experiencia fuese posible -la situación liminar, diremos- estaban situadas en la caída de la legitimidad de las instituciones.

En este escenario fue que el agua de las demandas, del malestar, colapsó la sala de máquinas. Sin embargo, el efecto es potencialmente importante. La crisis a nivel institucional es también una puerta para la ciudadanía. Y aparentemente decidieron pasar por ella. ¿Puede esto (la incorporación a la vida política de la sociedad civil) configurar una nueva transición a la democracia, esta vez de corte social? La transición política ha terminado en fechas distintas según cada uno de los transitólogos que emergieron en Chile. Sugerimos aquí la muerte de Pinochet como punto final, que es lo mismo que decir el día de la muerte de la Concertación, aunque esta sobreviviera adornada con el carisma de Bachelet. Pero una coalición que termina un gobierno con $80 \%$ de aprobación y obtiene solo un cuarto de los votos en primera vuelta es objetivamente una coalición

37. Definida así por Jeffrey Alexander. Ver al respecto Alexander, J., Sociología Cultural. Formas de clasificación en las sociedades complejas, Barcelona: Anthropos, 2000. 
muerta, como ya queda en evidencia en los días que corren. Pues bien, la transición política ya terminó. Pero no ha ocurrido la transición social a la democracia. Los meses de mayo y junio de 2011, sin embargo, han implicado una escalada de energía de la ciudadanía, que ha salido a las calles generando perplejidad de algunos y rabia de otros. Este hecho, que de momento es un síntoma y una expectativa respecto al futuro, puede configurarse más allá de la dimensión de una protesta en tanto significante.

\section{¿ESPASMO, AGONÍA O REVITALIZACIÓN? LA POLITIZACIÓN DE LO SOCIAL}

Durante los gobiernos de la Concertación, las movilizaciones sociales fueron fundamentalmente espasmos, eventos sin inercia posterior, imposibles de perpetuar sus dinámicas. ¿Es el actual movimiento social (no solo estudiantil) un espasmo? La ausencia de otras experiencias le da pocas probabilidades a la superación del espasmo. Pero este evento ha durado demasiado para carecer de rasgos superiores. También podría ser este acto de resistencia el último de un conjunto de eventos. Cuando un cuerpo lucha antes de morir, en la agonía, se acumulan todas las fuerzas restantes e intentan arribar a la línea que permite conservar la vida. Conocido como el canto del cisne, el último exabrupto, el último estertor, la última conquista; surge entonces la pregunta obvia: ¿puede ser el actual movimiento el canto del cisne de la educación pública chilena y de las resistencias a todas las formas de mercantilización y privatización? Es posible. Hoy las energías se ven reunidas, pero su desgaste es probable y conquistar la esfera de las decisiones no es un camino fácil ni mucho menos breve.

Si las instituciones no hubiesen caído putrefactas, si esos dioses no hubiesen muerto, probablemente las tesis del espasmo o la agonía serían las únicas válidas. Pero hay espacio para pensar la transformación. Hoy no parece tan inverosímil impugnar la estructura impositiva. Hoy no parece tan lejano discutir sobre la Constitución Política. No se puede decir que haya despertado la utopía social, pero sí resulta viable señalar que los ciudadanos han estado dispuestos a correr el cerco luego que este se había caído. Y ello supone inercia, nuevas lógicas, todo lo cual está por producirse. No es una ruta que goce de probabilidad mirando los últimos años, pero la inercia generada entre mayo y junio de 2011 da para pensar en cambios. Por supuesto, más relevante a la hora de entender la forma en que se mueve este clivaje, no se aprecia por dónde restituirán su legitimidad las instituciones.

Estos movimientos sociales no son ni del viejo ni del nuevo tipo. Los antiguos operaban sobre la contradicción central del capitalismo: la relación entre burguesía y proletariado, empresario y trabajador. El clivaje era la relación con el capital. Los nuevos operaron fundamentalmente en las relaciones identitarias y el desarrollo de resistencias o búsquedas de cambios culturales sobre densas temáticas que, en cualquier caso, resultan en principio ajenas a la contradicción central del capitalismo (género, etnias, minorías sexuales, en fin). El movimiento social en Chile tiene de lo primero y lo segundo, pero no es ninguno de los dos. La huella central de este movimiento radica en la problemática relación con la dimensión económica de la circulación. La teoría marxista 
establece la existencia del plusvalor en la dimensión de la producción. Sin embargo, en Chile la forma en que se ha mercantilizado cada dimensión de la vida y la sobrevida ha supuesto una existencia de formas de generación de plusvalor también en la dimensión de la circulación, generando mercados basados en la insustentabilidad. El mundo del retail se financia de los insolventes, que son más pobres, beneficiando el acceso de bienes a los más ricos. El mercado bursátil vive de las AFPs, fuente inagotable de recursos para invertir, que no son sino montos obligatorios y por tanto impuestos concesionados a privados. Los estudiantes están obligados en la práctica a endeudarse para estudiar y por tanto tienen que presionar su propia vida para financiar no ya una industria (educación), sino dos (bancos además). Considerando que las utilidades de unos y otros pueden incluso aproximarse hasta el 40\%, se comprenderá el carácter socialmente insustentable de un sistema económico plenamente sustentable en sí. En este escenario es que surge este movimiento. El carácter obligatorio de la libertad de mercado ha mostrado su rostro. Los chilenos habían aceptado pagar por educación como nadie en el planeta. Habían aceptado la privatización total de la energía y las aguas. Pero no parecen tan dispuestos a aceptar la mercantilización que va sobre la privatización: la conversión de la deuda educacional en otro negocio increíble, el carácter imperativo de la construcción de una represa como única solución para el país. El mercado se ha mostrado violento y opresivo. Y el mercado hoy tiene representantes legales: un gobierno de empresarios.

El presente movimiento social no es de rebelión, sino de resistencia. No nace contra lo existente, nace del esfuerzo del gobierno por profundizar un modelo que no es aceptado socialmente. Se apoyaba, el gobierno, en la experiencia previa, despolitizadora y desmovilizadora. Sin embargo, ya se ha gatillado la ruta de politización del malestar. Y todo proceso tiene su inercia. Y toda historia tiene su péndulo; ¿habrá tocado Chile el extremo de despolitización? ¿Se reiniciará la política?

En Chile se había olvidado un principio de toda democracia: que la ciudadanía se construye en un espacio intersticial y fino que se ubica entre cualquier cáliz y el sinfín posible de espadas. Todo incremento en el poder del cáliz es una merma al ciudadano, como todo incremento en el poder de la espada. Rodeado por el poder espiritual y el terrenal, la ciudadanía solo se consuma como tal en la usurpación de territorios a ambos límites. Es cierto que siempre la ciudadanía es una ficción, nunca es absoluta, siempre debe convocar formas de violencia simbólica o física, siempre en algún punto llamará al cáliz o la espada, pero la ampliación de esa ficción, su anchura, su fuerza para proyectarse sobre la materia, es condición necesaria para la búsqueda del logro más difícil de toda sociedad dinámica: la igualdad.

Es momento de retornar a la distinción de las tres dimensiones de la política. El palacio, las políticas públicas y la polis. La transición a la democracia en Chile aconteció en el palacio. Desde él se diseñó un modelo de políticas públicas disociado del espíritu democrático, sino más bien asociado a la búsqueda de nociones de eficacia y eficiencia propias de la visión económica dominante. Las políticas públicas, por tanto, tuvieron transformación, pero no transición democrática, como quedó explicitado en el Transantiago. La ciudadanía, en la polis, no vivió ninguna transición democrática. Ningún poder se distribuyó y objetivamente incluso ha perdido poder desde la dictadura; hay más anomia en 
general, los indicadores de desigualdad (y ello es diferencial de poder) han aumentado, el tejido social ha sido suplantado por su falso profeta: la inclusión en el mercado. A esto sumamos el dique entre lo social y lo político, mediado por las instituciones, y comprendemos que la transición democrática comenzó y terminó en el palacio, en las coaliciones de gobierno, en la reordenación de las posibles castas gubernamentales.

Todos los caminos conciernen a los hechos. Todos los hechos conciernen a los objetos. Todos los objetos conciernen a los hombres. La suma de todos los caminos, de todos los hechos, de todos los hombres; eso es la política. Y eso es precisamente lo que parece haber salido a la calle.

\section{REFERENCIAS BIBLIOGRÁFICAS}

Alexander, J., Sociología cultural. Formas de clasificación en las sociedades complejas, Barcelona: Anthropos, 2000.

Bauman, Z., La posmodernidad y sus descontentos, Madrid: Ediciones Akal, 2001.

Bauman, Z., En busca de la política, México: Fondo de Cultura Económica, 2002.

Bauman, Z., Modernidad y ambivalencia, Barcelona: Anthropos, 2005.

Beck, U., La sociedad del riesgo global, Madrid: Siglo XXI, 2009.

Boltanski, Luc y Chiapello, Eve, El nuevo espiritu del capitalismo, Madrid: Ediciones Akal, 2002.

CIES Universidad de Chile: El Chile Profundo. Cultura de la desigualdad en el Chile Contemporáneo, Santiago: Documento de trabajo CIES, síntesis en www.ciesmilenio.cl, 2010.

CIES Universidad de Chile: Siete Fenómenos sobre Educación y Desigualdad en Chile, Santiago: Documento de trabajo CIES, 2010. URL: http://www.ciesmilenio.cl/wp-content/ uploads/2011/03/DESIGUALDAD-Y-EDUCACION-INFORME-CIES-U-DE-CHILE.pdf

Durkheim, É., El suicidio, Madrid: Akal, 1985.

Habermas, J., Facticidad y validez. Sobre el derecho y el Estado democrático de derecho en términos de teoría del discurso, Madrid: Trotta, 1998.

Jirón, M., et. Al., "Consumo de Antidepresivos en Chile entre 1992 y 2004", en Revista Médica de Chile, $\mathrm{N}^{a}$ 136, Santiago: 2008, págs. 1147-1154.

Lechner, N., Obras escogidas. Vol. 1, Santiago de Chile: LOM, 2006.

Lipovetsky, G., La Sociedad de la Decepción. Barcelona: Anagrama, 2008.

Luhmann, N., "La contingencia como valor propio de la sociedad moderna", en Observaciones de la modernidad. Racionalidad y contingencia en la sociedad moderna, Barcelona; Paidós, 1997.

Programa de Naciones Unidas para el Desarrollo, Informe de Desarrollo Humano 2010. La verdadera riqueza de las naciones: Caminos al desarrollo humano, Madrid: Ediciones Mundi-Prensa, 2010.

Rojas, I., Presentación "Plan Nacional de Prevención del Suicidio" en Jornada Suicidio en Chile, Perspectivas Actuales, Santiago: Pontificia Universidad Católica de Chile, Abril 2008. URL: http://www.psiquiatriauc.cl/system/files/Jornada-Suicidio_Presentacion_Sra_Irma_Rojas. pdf

Sennett, R., La cultura del nuevo capitalismo, Barcelona: Anagrama, 2006.

Sennett, R., El declive del hombre público, Barcelona: Anagrama, 2011.

Stiglitz, J., El Malestar en la Globalización, Madrid: Taurus, 2002.

Postfacio, en Revista de Sociología, Na 21, Santiago: Departamento de Sociología de la Universidad de Chile, 2007, págs. 278-279. 